\title{
Unit of Length
}

National Cancer Institute

\section{Source}

National Cancer Institute. Unit of Length. NCI Thesaurus. Code C42578.

An indication of the type of unit of measure being used to express a length or distance. 